\title{
Intra-ocular pressure measurements using the Ocular Response Analyser and ICare tonometer: A comparison
}

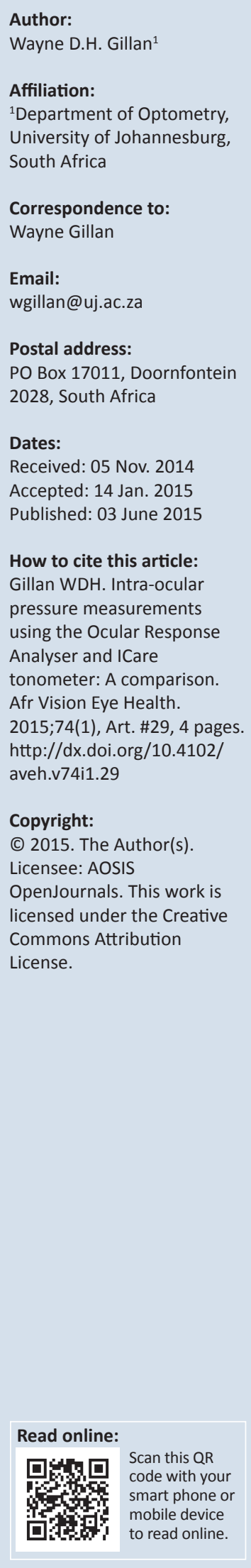

The accurate measurement of intra-ocular pressure (IOP) is an important procedure in the detection and treatment of glaucoma. The Ocular Response Analyser (ORA) and the ICare rebound tonometer are two recent additions to the instruments available to eye care practitioners for the measurement of IOP. The present study investigated whether the ORA and the ICare tonometer can be used interchangeably. Twenty-eight subjects had three measures of IOP taken using the two instruments. The ORA provides two different measures of IOP - Goldmann and cornea compensated IOP - whilst the ICare tonometer provides IOP only. The results of this study suggest that only the ORA Goldmann and ICare IOP measures are comparable. In general, it is advisable not to use the ORA and ICare tonometers interchangeably.

\section{Introduction}

Glaucoma is a ubiquitous and common disease that is considered to be a major cause of blindness. ${ }^{1}$ Intra-ocular pressure (IOP) might be the most important risk factor in the development of glaucoma, with the measurement of IOP remaining an important probe in the clinical investigation, and care, of patients with (or suspected of having) glaucoma ${ }^{2}$ or raised IOP. Goldmann applanation tonometry (GAT) has long been considered to be the gold standard for the measurement of IOP., ${ }^{3,4}$ Chihara $^{5}$ has suggested that 'a difference as small as only $1 \mathrm{mmHg}$ in the mean IOP is important for patients with glaucoma'. However, Chihara also stated that Goldmann tonometry is 'not precise enough to measure the true IOP within an error of $1 \mathrm{mmHg}^{\prime}$ and suggests that Goldmann tonometry can be affected by corneal thickness, corneal curvature, modulus of elasticity of the cornea and the tear film. ${ }^{5}$ The question is whether GAT is the best indicator available of IOP; does GAT provide the most accurate (true IOP) indication of IOP? New, non-applanating tonometers have been developed (including the ICare rebound tonometer, dynamic contour tonometer and the Ocular Response Analyser [ORA], for example) that might surpass GAT as the gold standard for the measurement of IOP. ${ }^{5}$

The ICare tonometer is a recently introduced rebound tonometer that does not require anaesthesia of the cornea. Kontiola ${ }^{6}$ credits Obbink with introducing the idea of dynamic (rebound) tonometry. Kontiola ${ }^{6}$ improved on the principles proposed by Obbink, presenting an improved instrument/method for measuring IOP. The resulting ICare rebound tonometer received CE (Conformité Européene, or European Commission) approval in 2003.7 The basic mechanism of the ICare tonometer consists of a solenoid and a magnetised probe that moves forward, hitting the cornea and rebounding. The solenoid detects the motion, impact and rebound of the probe, and converts the speed of the probe into a measurement of IOP. ${ }^{8}$ Numerous reports have been published comparing the ICare tonometer with GAT, with many finding that the ICare tonometer compares well with GAT.9,10,11,12,13,14 The ORA 'utilizes a dynamic bi-directional applanation process to measure biomechanical properties of the cornea and the intraocular pressure of the eye $^{\prime} .{ }^{15}$ The instrument uses an air pulse to cause indentation of the cornea, resulting in an inward as well as an outward movement of the corneal surface. Four measurements are determined during one air pulse: Goldmann-correlated IOP $\left(\mathrm{IOP}_{\mathrm{g}}\right)$, corneal compensated IOP (IOP $\mathrm{cc}_{\mathrm{cc}}$ ), corneal hysteresis $(\mathrm{CH})$ and corneal resistance factor $(\mathrm{CRF}) .{ }^{1}$ The reader is referred elsewhere for a detailed exposition of how the ORA measurements are calculated and determined. ${ }^{15,16,17}$ Several reports comparing the ORA with the GAT have been produced. ${ }^{2,16,17,18,19,20}$ A study by Lam et al. ${ }^{20}$ showed that the ORA produced measurements that were similar to GAT measurements, whilst the ORA was shown by others $2,16,17,18,19$ to agree poorly with GAT measurements. The ICare tonometer and GAT have been compared with various types of non-contact tonometer (NCT) as well, ${ }^{9,21}$ with the NCTs agreeing less favourably than the ICare tonometer when compared with GAT. Vandewalle et al., ${ }^{2}$ comparing ICare, ORA and GAT, showed that ORA measurements did not agree well with ICare or GAT measurements. 
The aim of the present investigation was to compare ORA and ICare tonometer measurements of IOP to determine if the two instruments can be used interchangeably.

\section{Method}

The data used in this report were obtained from a larger study of diurnal variation and reproducibility of IOP measurements. Twenty-eight healthy subjects (nineteen women and nine men), aged between 18 and 65 years, gave written informed consent to take part in the study, to which the tenets of the Declaration of Helsinki were applied. In the original study, four measurement sessions were obtained: the ORA and ICare tonometer were used to acquire three measures of IOP for the right and left eyes of each subject. Measurements were taken during a morning session and, on the same day, 8 hours later, an afternoon session. One week later, at approximately the same time of day, another morning measurement session was followed 8 hours later by an afternoon measurement session. The means of the 3 IOP measurements were calculated for each subject. The ORA produced two measures of IOP, namely IOP $\mathrm{g}_{\mathrm{g}}$ and IOP $\mathrm{cc}^{\prime}$ whilst the ICare tonometer gave a 'normal' IOP measure. While taking the measurements, manufacturer instructions for the use of each instrument were adhered to. The order in which the two instruments were used on each subject was randomised by means of a coin throw.

In comparing the ORA and ICare tonometers, only one session's measurements were analysed. The measurement sessions (first to fourth, inclusive) to be used for analysis were determined randomly, and the first measurement session (obtained in the morning of the first week) was chosen. When having the choice of using measurements obtained from the right and left eyes of the same individuals, a potential problem arises because many measurements of right and left eyes are either symmetrical or they are well correlated. Several articles discuss the difficulties that may be experienced when combining right and left eyes or only using one (right or left) set of data when both sets of data are available. ${ }^{22,23,24,25}$ Using the recommendations of Armstrong, ${ }^{22}$ an intra-class correlation coefficient (ICC) was determined between the relevant sets of data for right and left eyes. The relevant ICCs were found to deviate from unity (or 1) which meant that the data from right and left eyes could not be combined or averaged. ${ }^{22}$ In the present study, right and left eye data were used separately to investigate the comparison of the two instruments, namely the ORA and the ICare tonometer.

In summary, the right and left eye data (for 28 subjects), collected from the ORA and ICare tonometers, were analysed separately and not combined in any way. Only measurements taken during the morning session of the first week were included. The MedCalc statistics software package was used to analyse the data.

\section{Results}

Table 1 presents the descriptive statistics for the data used in this study. The mean of each type of IOP measure, for right and left eyes, is given, namely: ORA cornea compensated IOP (IOP $\left.{ }_{c c}\right)$, ORA Goldman IOP $\left(\right.$ IOP $\left._{g}\right)$ and ICare IOP $\left(\mathrm{IOP}_{\mathrm{ic}}\right)$. Included are the standard deviations (s.d.) and $95 \%$ confidence limits on the mean $(95 \% \mathrm{CI})$. The results of the Kolmogorov-Smirnov test for normal distribution of the data indicated that all data were normally distributed.

The results of a repeated-measures analysis of variance (ANOVA) are shown in Table 2, where significant differences between means are found for three of the six comparisons, all at the $95 \%$ confidence level.

The mean differences, or bias (with the relevant 95\% confidence interval on the mean difference), between the different measures of IOP are given in Table 3. Included are the upper and lower limits for all measurements as well as the $95 \%$ confidence interval on the mean difference.

Figures 1 and 2 show Bland-Altman plots for $\mathrm{IOP}_{c c} \mathrm{R}$ versus $\mathrm{IOP}_{\mathrm{ic}} \mathrm{R}$ and $\mathrm{IOP}_{\mathrm{g}} \mathrm{L}$ versus $\mathrm{IOP}_{\mathrm{ic}} \mathrm{L}$ respectively (representing examples of data showing a significant difference between means [Figure 1] and the other showing no significant

TABLE 1: Descriptive statistics for the data collected from 28 subjects.

\begin{tabular}{|c|c|c|c|c|c|c|}
\hline Descriptive statistics & $\mathrm{IOP}_{\mathrm{cc}} \mathrm{R}$ & $\mathrm{IOP}_{\mathrm{g}} \mathrm{R}$ & $\mathrm{IOP}_{\mathrm{ic}} \mathrm{R}$ & $\mathrm{IOP}_{\mathrm{cc}} \mathrm{L}$ & $10 P_{g} \mathrm{~L}$ & $\mathrm{IOP}_{\mathrm{ic}} \mathrm{L}$ \\
\hline Mean IOP & 18.31 & 16.31 & 15.76 & 17.08 & 15.30 & 15.98 \\
\hline s.d. & 3.80 & 3.25 & 2.93 & 2.90 & 3.18 & 3.68 \\
\hline $95 \% \mathrm{Cl}$ & $16.8-19.8$ & $15.1-17.6$ & $14.6-16.9$ & $15.9-18.2$ & $14.1-16.5$ & $14.5-17.4$ \\
\hline
\end{tabular}

All measurements are in $\mathrm{mmHg}$

$\mathrm{R}$, right eye data; L, left eye data; Mean IOP, the mean of three measurements for each IOP measurement; s.d., standard deviation; $95 \% \mathrm{Cl}$, the $95 \%$ confidence interval on the mean.

TABLE 2: Results of a repeated-measures analysis of variance for the right and left eyes.

\begin{tabular}{|c|c|c|}
\hline Comparisons & $p$ & Different? \\
\hline$I O P_{c c} R$ versus $I O P_{g} R$ & 0.0033 & Yes \\
\hline$I O P_{c c} R$ versus $I O P_{i c} R$ & 0.0033 & Yes \\
\hline $1 O P_{\mathrm{g}} \mathrm{R}$ versus $10 \mathrm{P}_{\mathrm{ic}} \mathrm{R}$ & 0.89 & No \\
\hline $1 O P_{c c} \mathrm{~L}$ versus $1 O P_{g} \mathrm{~L}$ & $<0.0001$ & Yes \\
\hline $1 O P_{c c} \mathrm{~L}$ versus $10 P_{i c} \mathrm{~L}$ & 0.20 & No \\
\hline $1 O P_{\mathrm{g}} \mathrm{L}$ versus $1 O P_{\mathrm{ic}} \mathrm{L}$ & 0.55 & No \\
\hline
\end{tabular}

TABLE 3: Mean differences between IOP measures, $95 \%$ confidence intervals on the mean difference, and the upper and lower limits for all measurements.

\begin{tabular}{lcccc}
\hline Comparisons & Mean difference & $\mathbf{9 5 \%} \mathrm{Cl}$ & Upper limit & Lower limit \\
\hline $\mathrm{IOP}_{\mathrm{cc}} \mathrm{R}$ versus $I O \mathrm{P}_{\mathrm{g}} \mathrm{R}$ & 2.0 & $0.88-3.12$ & 7.68 & -3.68 \\
$\mathrm{IOP}_{\mathrm{cc}} \mathrm{R}$ versus $I O \mathrm{P}_{\mathrm{ic}} \mathrm{R}$ & 2.55 & $1.23-3.96$ & 9.70 & -4.61 \\
$\mathrm{IOP}_{\mathrm{g}} \mathrm{R}$ versus $\mathrm{IOP}_{\mathrm{ic}} \mathrm{R}$ & 0.55 & $-0.51-1.56$ & 5.87 & -4.78 \\
$\mathrm{IOP}_{\mathrm{cc}} \mathrm{L}$ versus $I O P_{\mathrm{g}} \mathrm{L}$ & 1.77 & $1.21-2.35$ & 4.65 & -1.10 \\
$\mathrm{IOP}_{\mathrm{cc}} \mathrm{L}$ versus $I O P_{i c} \mathrm{~L}$ & 1.10 & $-0.09-2.29$ & 7.11 & -4.91 \\
$\operatorname{IOP}_{\mathrm{g}} \mathrm{L}$ versus $I \mathrm{P}_{\mathrm{ic}} \mathrm{L}$ & -0.67 & $-1.69-0.34$ & 4.45 & -5.80 \\
\hline
\end{tabular}




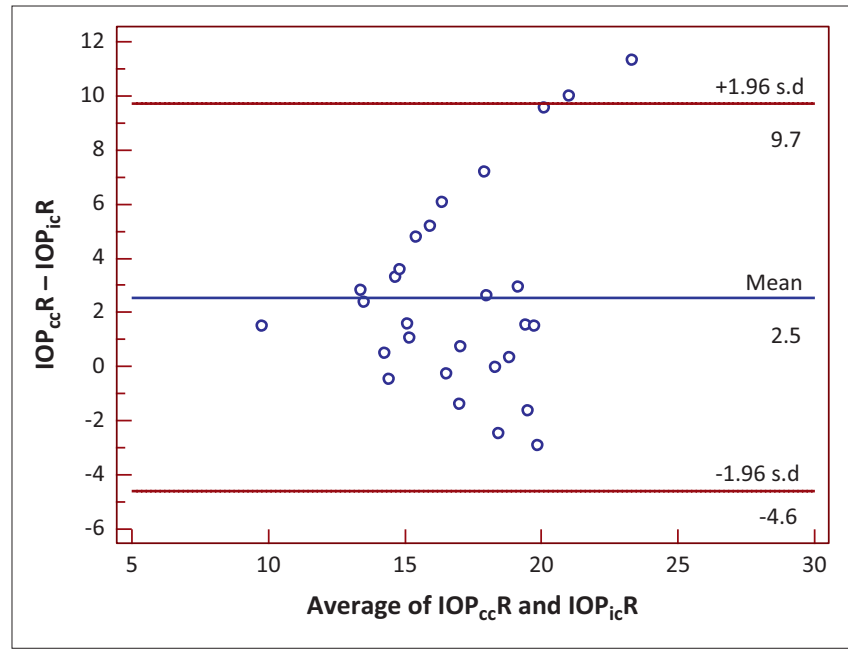

FIGURE 1: A Bland-Altman plot for IOP $R$ versus $I O P_{i c} R$. The mean difference between the two IOP measures is $2.55 \mathrm{mmHg}$.

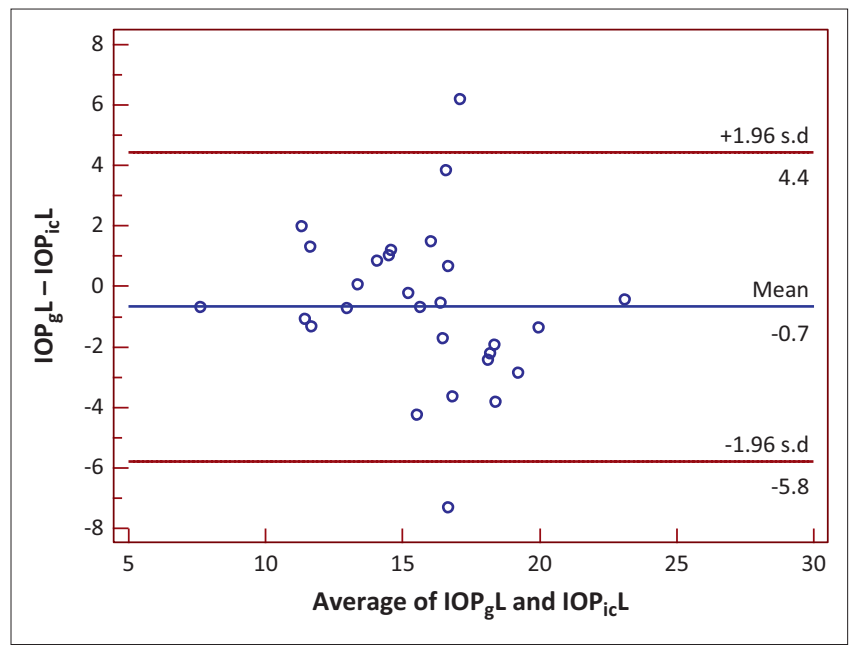

FIGURE 2: A Bland-Altman plot for IOP $L$ versus IOP $\mathrm{L}$ is shown. The mean difference between the two IOP measures is $-0.67 \mathrm{mmHg}$.

difference between means [Figure 2]). In Figure 1, the mean difference (solid blue line labelled 'Mean') between the IOP measures for the two instruments is $2.55 \mathrm{mmHg}$. The dotted red lines indicate the 95\% limits of agreement for all measurements (95\% of all future measurements would be expected to fall between these limits); in this case, the range between the upper and lower limits is $14.31 \mathrm{mmHg}$. Figure 2 shows a Bland-Altman plot (IOP $\mathrm{L}$ versus $\mathrm{IOP}_{\mathrm{ic}} \mathrm{L}$ ) where the mean difference between IOP measures is $-0.67 \mathrm{mmHg}$ and the range between upper and lower limits is $10.25 \mathrm{mmHg}$.

\section{Discussion}

The accurate measurement of IOP is important in the diagnosis and treatment of glaucoma. GAT is considered the gold standard against which all other tonometers are compared. New tonometer designs have recently become available in an attempt to improve the accuracy and efficiency of tonometry. 5,6 The present study compares IOP measurements taken with the ORA and the ICare tonometer. Both these tonometers provide measures of IOP within $1 \mathrm{mmHg}$ (whether the measurements are an accurate indicator of true IOP remains unclear), an attribute that Chihara $^{5}$ states is missing from GAT measurements. The question remains, however, whether the ORA and ICare tonometer can be used interchangeably when measuring IOP in humans. Table 1 shows mean IOPs obtained from the ORA and ICare tonometers. The largest mean difference between IOP measurements is $2.55 \mathrm{mmHg}$, and the smallest mean difference is $0.55 \mathrm{mmHg}$ (see Table 3). If $1 \mathrm{mmHg}$ accuracy is important in the measurement of IOP, ${ }^{5}$ it follows that, for most comparisons, these two instruments would seem not to be interchangeable for measuring IOP. Table 2 shows data indicating that only $\mathrm{IOP}_{\mathrm{g}}$ and $\mathrm{IOP}_{\mathrm{ic}}$ means (for both right and left eyes) were consistently found not to be significantly different at a $95 \%$ confidence level. Figures 1 and 2 show Bland-Altman plots for IOP $\mathrm{R}$ and $\mathrm{IOP}_{\mathrm{ic}} \mathrm{R}$, and $\mathrm{IOP}_{\mathrm{g}} \mathrm{L}$ and $\mathrm{IOP}_{\mathrm{ic}} \mathrm{L}$ respectively, as examples. The mean difference between IOP ${ }_{c c} R$ and IOP ${ }_{i c} R$ in Figure 1 is $2.55 \mathrm{mmHg}$ (shown by the solid blue line labelled 'Mean'), whilst Figure 2 shows the mean difference between $\mathrm{IOP}_{\mathrm{g}} \mathrm{L}$ and $\mathrm{IOP}_{\mathrm{ic}} \mathrm{L}$ to be $-0.7(-0.67) \mathrm{mmHg}$. Bland-Altman analysis suggests that only $\mathrm{IOP}_{\mathrm{g}}$ and $\mathrm{IOP}_{\text {ic }}$ might, in fact, be interchangeable, a contention that is supported in Table 2 where these two means are not significantly different for both right and left eyes. Vandewalle et al. ${ }^{2}$ have shown that ORA and ICare measurements of IOP do not agree well, and the present study supports their findings. In a study comparing nine different tonometers, De Moraes et al. ${ }^{26}$ conclude by stating: 'It is important to emphasize that the IOP readings from these devices are not interchangeable ...' and 'Rather than using multiple devices in the same patient, the clinician should choose one that better fits each clinical indication and use it consistently'. In conclusion, the data collected in the present study do not, in general, support the interchangeable use of the ORA and the ICare tonometers.

\section{Acknowledgements}

My thanks to N. Chothia, S. Jogee, R. Varachia, Y. Najam, N. Mahomed and N. Badat (final-year optometry students) for data collection.

\section{Competing interests}

The author declares that he has no financial or personal relationships which might have inappropriately influenced him in writing this article.

\section{References}

1. Quigley HA, Broman AT. The number of people with glaucoma worldwide in 2012 and 2020. Br J Ophthalmol. 2006;90:262-267. http://dx.doi.org/10.1136/ bjo.2005.081224

2. Vandewalle E, Vandenbroeck S, Stalmans I, Zeyen T. Comparison of ICare, dynamic contour tonometer and ocular response analyzer with Goldmann applanation tonometer in glaucoma. Euro J Ophthalmol. 2009;19:783-789.

3. European Glaucoma Society. Terminology and guidelines for glaucoma. 3rd ed Savona, Italy: Dogmap, 2008; pp. 61-66.

4. Kass MA. Standardizing the measurement of intraocular pressure for clinical research. Guidelines from the eye care technology forum. Ophthalmol. 1996;103:183-185. http://dx.doi.org/10.1016/S0161-6420(96)30741-0 
5. Chihara E. Assessment of true intraocular pressure: The gap between theory and practical data. Surv Ophthalmol. 2008;53:203-218. http://dx.doi.org/10.1016/j. survophthal.2008.02.005

6. Kontiola Al. A new induction-based impact method for measuring intraocular pressure. Acta Ophthalmol Scand. 2000;78:142-145. http://dx.doi.org/10.1034/j. 1600-0420.2000.078002142.x

7. Harvey B. A contact tonometer without anaesthetic: The Tiolet ICare. Optician. 2004;228:No. 5974.

8. Jorge J, Fernandes P, Queirós A, Ribeiro P, Garcês G, Gonzales-Meijome JM Comparison of the IOpen and ICare rebound tonometers with the Goldmann tonometer in a normal population. Ophthal Physiol Opt. 2010;30:108-112. http://dx.doi.org/10.1111/j.1475-1313.2009.00697.x

9. Nakamura N, Darhad U, Tatsumi Y, et al. Agreement of rebound tonometer in measuring intraocular pressure with three types of tonometer. Am J Ophthalmol. 2006;142:332-334. http://dx.doi.org/10.1016/j.ajo.2006.02.035

10. Gandhi NG, Prakalapakorn SG, El-Dairi MA, Jones SK, Freedman SF. Icare ONE rebound versus Goldmann applanation tonometry in children with known or suspected glaucoma. Am J Ophthalmol. 2012;154:843-849. http://dx.doi. org/10.1016/j.ajo.2012.05.003

11. Pakrou N, Gray T, Mills R, Landers J, Craig J. Clinical comparison of Icare tonometer and Goldmann applanation tonometry. J Glaucoma. 2008;17:43-47. http://dx.doi.org/10.1097/IJG.0b013e318133fb32

12. Moreno-Montañés J, García N, Fernández-Hortelano A, García-Layana A. Rebound tonometer compared with Goldmann tonometer in normal and pathologic corneas. Cornea. 2007;26:427-430. http://dx.doi.org/10.1097/ icO.0b013e318030df6e

13. Munkwitz S, Elkarmouty A, Hoffman EM, Pfeiffer N, Theime H. Comparison of the ICare rebound tonometer and the Goldmann applanation tonometer over a wide IOP range. Graefes Arch Clin Exp Ophthalmol. 2008;246:875-879. http://dx.doi. org/10.1007/s00417-007-0758-3

14. Fernandes P, Díaz-Rey JA, Queirós A, Ganzolez-Meijome JK, Jorge J. Comparison of the Icare rebound tonometer with the Goldmann tonometer in a normal population. Ophthal Physiol Opt. 2005;25:436-440. http://dx.doi.org/10.1111/ j.1475-1313.2005.00327.x

15. Reichert ORA. pamphlet/brochure. c2010 [cited 03 Nov 2010]. Available from http://www.ocularresponseanalyzer.com
16. Martinez-de-la-Casa JM, Garcia-Feijoo J, Fernandez-Vidal A, Mendez-Hernandez C, Garcia-Sanchez J. Ocular response analyzer versus Goldmann applanation tonometry for intracular pressure measurements. Inv Ophthalmol Vis Sci. 2006;47:4410-4414. http://dx.doi.org/10.1167/iovs.06-0158

17. Feizi S, Hashemloo A, Rastegarpour A. Comparison of the ocular response analyzer and the Goldmann applanation tonometer for measuring intraocular pressure after deep anterior lamellar keratoplasty. Inv Ophthalmol Vis Sci. 2011;52: 5887-5891. http://dx.doi.org/10.1167/iovs.10-6771

18. Kotecha A, Elsheikh A, Roberts CR, Zhu H, Garway-Heath DF. Corneal thickness and age-related biomechanical properties of the cornea measured with the Ocular Response Analyzer. Inv Ophthalmol Vis Sci. 2006;47:5337-5347. http://dx.doi. org/10.1167/iovs.06-0557

19. Lau W, Pye D. A clinical description of ocular response analyzer measurements. Inv Ophthalmol Vis Sci. 2011;52:2911-2916. http://dx.doi.org/10.1167/iovs.10-6763

20. Lam A, Chen D, Chiu R, Chui W-S. Comparison of IOP measurements between ORA and GAT in normal Chinese. Optom Vis Sci. 2007;84:909-914. http://dx.doi. org/10.1097/OPX.0b013e3181559db2

21. Van Der Jagt LH, Jansonius NM. Three portable tonometers, the TGDc-01, the Icare and the Tonopen XL, compared with each other and with Goldmann applanation tonometry. Ophthal Physiol Opt. 2005;25:429-435. http://dx.doi.org/10.1111/ j.1475-1313.2005.00318.x

22. Armstrong RA. Statistical guidelines for the analysis of data obtained from one or both eyes. Ophthal Physiol Opt. 2012;33:7-14. http://dx.doi.org/10.1111/ opo.12009

23. Karakosta A, Vassilaki M, Plainis S, Elfadl NH, Tsilimbaris M, Moschandreas J. Choice of analytic approach for eye-specific outcomes: one eye or two? Am Ophthalmol. 2012;153:571-579. http://dx.doi.org/10.1016/j.ajo.2011.08.032

24. Newcombe RG, Duff GR. Eyes or patients? Traps for the unwary in the statistical analysis of ophthalmological studies. Br J Ophthalmol. 1987;71:645-646. http://dx.doi.org/10.1136/bjo.71.9.645

25. Armstong RA, Davies LN, Dunne MCM, Gilmartin B. Statistical guidelines for clinical studies of human vision. Ophthal Physiol Opt. 2011;31:123-136. http://dx.doi.org/10.1111/j.1475-1313.2010.00815.x

26. De Moraes CGV, Prata TS, Liebmann J, Ritch R. Modalities of tonometry and their accuracy with respect to corneal thickness and irregularities. J Optom. 2008;1: 43-49. http://dx.doi.org/10.3921/joptom.2008.43 